\title{
Efeito da irradiação gama nas características físico-químicas e sensoriais do arroz (Oryza sativa L.) e no desenvolvimento de Sitophilus oryzae L.
}

\author{
Effect of gamma irradiation on physico-chemical and sensorial characteristics \\ of rice (Oryza sativa L.) and on the development of Sitophilus oryzae L.
}

\author{
Cíntia Fernanda Pedroso ZANÃO ${ }^{1}$, Solange Guidolin CANNIATTI-BRAZACA ${ }^{1 *}$, \\ Silene Bruder Silveira SARMENTO ${ }^{1}$, Valter ARTHUR ${ }^{2}$
}

\section{Resumo}

A pesquisa teve como objetivo verificar a viabilidade da radiação gama como método de conservação do arroz polido (Oryza sativa L.). As amostras foram irradiadas com doses 0,5; 1,0; 3,0; e 5,0 kGy. Foram realizadas análises da quebra do grão no beneficiamento, da longevidade e reprodução do Sitophilus oryzae L., a composição centesimal, o conteúdo de amilose aparente e propriedades de pasta dos amidos, e análises para cor (instrumental) e análise sensorial do arroz cru e cozido. Foi utilizado teste de Tukey $(\mathrm{p} \leq 0,05)$ para verificar a diferença estatística entre os tratamentos. A irradiação não alterou a porcentagem de quebra dos grãos durante o beneficiamento e causou efeito negativo no desenvolvimento dos insetos. A irradiação não alterou de maneira significativa a composição centesimal e o conteúdo de amilose aparente. Os resultados da propriedade de pasta foram alterados, ocorrendo redução da temperatura de pasta, diminuição do tempo para ocorrência do pico viscosidade, redução nos valores de viscosidade máxima e viscosidade final e a tendência de retrogradação se tornou menos acentuada com o incremento das doses de irradiação. Foram detectadas diferenças no aspecto sensorial entre as amostras, sendo que a amostra irradiada com a dose de 1,0 kGy obteve maiores médias. Para os resultados da cor instrumental, foi observada diferença nos valores $\mathrm{b}^{\star}$, indicando que o arroz sofreu mudanças de branco para amarelado com o aumento da dose de irradiação. O tratamento com dose de 1,0 kGy foi a melhor dose para atingir o objetivo do trabalho.

Palavras-chave: arroz; irradiação; sensorial; amido; Sitophilus oryzae L.

\begin{abstract}
The objective of this research was to verify the viability of the gamma radiation as polished rice (Oryza sativa L.) conservation method. The samples were irradiated with doses of $0.5 ; 1.0 ; 3.0$; and $5.0 \mathrm{kGy}$. Analysis of the grain breakage during the enriching process, longevity and reproduction of the Sitophilus oryzae L., centesimal composition, apparent amylose content, starch paste properties, color (instrumental), and the sensorial evaluation of raw and cooked rice were performed. It was verified that the irradiation did not change the percentage of grain breakage during the enrichment process, and it caused a negative effect on the development of insects. The irradiation did not change significantly the centesimal composition and the apparent amylase content. The Tukey test $(\mathrm{p} \leq 0.05)$ was conducted to verify the differences between the treatments. Gamma irradiation affected the pasting properties of the rice flour. Pasting parameters as temperature, peak, final viscosity, and setback values showed decreasing values with irradiation doses. Differences were detected in the sensorial aspect among the samples, and the sample irradiated with the dose of $1.0 \mathrm{kGy}$ presented greater averages. Regarding the instrumental color parameter, it was observed the difference in the values $b^{*}$ indicating that the rice changed the white color for yellowish with the increase in the irradiation dose. The irradiation dose of $1.0 \mathrm{kGy}$ proved the best to meet the objectives of this study.

Keywords: rice; irradiation; sensorial; starch; Sitophilus oryzae L.
\end{abstract}

\section{Introdução}

O arroz está entre os mais importantes cereais cultivados e apresenta grande importância social (PEREIRA, 1996). Está presente nos países em desenvolvimento e é considerado um dos alimentos com melhor balanceamento nutricional, pois fornece $20 \%$ da energia e $15 \%$ da proteína "per capita" necessárias ao homem. O arroz é uma cultura extremamente versátil, que se adapta a diferentes condições de solo e clima, e é considerada a espécie de maior potencial de aumento de produção no combate à fome do mundo (GOMES; MAGALHÃES JÚNIOR, 2004).

Mas, quando o arroz é armazenado, sofre danos pelas mais diversas causas, tais como temperatura, umidade, ataque de roedores, microrganismos e insetos, sendo os insetos os prin-

Recebido para publicação em 11/6/2007

Aceito para publicação em 22/1/2008 (002596)

${ }^{1}$ Departamento de Agroindústria, Alimentos e Nutrição, Escola Superior de Agricultura "Luiz de Queiroz", Universidade de São Paulo - USP, Av. Pádua Dias, 11, CP 9, CEP 13418-900,Piracicaba -SP, Brasil, E-mail: sgcbrazaca@esalq.usp.br; cpedroso@claretianas.com.br; sgcbrazaca@esalq.usp.br; sbssarme@esalq.usp.br

${ }^{2}$ Laboratório de Irradiação de Alimentos e Radioentomologia, Centro de Energia Nuclear na Agricultura - CENA, Universidade de São Paulo - USP, Av. Centenário, 303, CEP 13416-000,CP 96, Piracicaba - SP,Brasil,E-mail: arthur@cena.usp.br

${ }^{*}$ A quem a correspondência deve ser enviada 
cipais causadores de grandes perdas qualitativas e quantitativas (MANCO, 1987).

A utilização contínua de defensivos químicos para o controle dessas pragas vem causando problemas como o surgimento de resistência a esses produtos (SARTORI et al., 1990). Além disso, outros inconvenientes do uso de defensivos químicos, como contaminação do ambiente, intoxicação de animais e do homem e ocorrência de resíduos tóxicos nos grãos, levam à necessidade de pesquisas com outros métodos de controle dessas pragas, dentro dos quais se destaca a irradiação.

O processo de irradiação de grãos é uma alternativa efetiva ao uso dos fumigantes químicos para o controle de insetos e outras pragas sujeito às barreiras fitossanitárias (TAIPINA et al., 2003).

O tratamento dos alimentos com radiações ionizantes apresenta ampla gama de efeitos benéficos, em particular o aumento do tempo de conservação, a destruição dos insetos, parasitos, bactérias patogênicas, fungos e leveduras; retardo da maturação e deteriorização de frutas; e a inibição de germinação de turbérculos e bulbos após a colheita (OMS, 1995; SATIN, 1997).

Em cereais a irradiação pode alterar as propriedades funcionais e afetar as características sensoriais como sabor e cor (URBAIN, 1986).

Como ingrediente principal do arroz, o amido confere estrutura, textura e consistência para muitos alimentos. A irradiação é considerada um método de modificação física do amido, penetrando pelo grânulo e causando maior dano à estrutura (BAO; AO; JANE, 2005).

A radiação gama pode ser considerada uma técnica de modificação do amido. Ela pode gerar radicais livres nas macromoléculas e estes são capazes de hidrolisar ligações químicas e, com isto, quebrar essas grandes moléculas em pequenos fragmentos de dextrina. Estas mudanças podem afetar as propriedades físicas e reológicas de cereais como o arroz, trigo e o milho (YU; WANG, 2007).

Sirisoontaralak e Noomhorm (2006) observaram que a irradiação de arroz aromático causou decréscimo em algumas propriedades de pasta, aumento na absorção de água e do teor de sólidos na água de cocção. Além destes, houve intensificação na coloração amarela e decréscimo na dureza do arroz cozido. $\mathrm{Na}$ análise sensorial, entretanto, os avaliadores perceberam de forma sutil tais alterações.

Yu e Wang (2007) observaram que os grânulos de amido foram destruídos com a irradiação e a quebra da viscosidade aumentou com a dose crescente. O efeito da irradiação na microestrutura do endosperma interno foi maior que no endosperma externo. Os parâmetros do RVA (Rapid Visco Analyser) foram diminuídos com a dose crescente, devido à quebra dos grânulos de amido causada pela irradiação.

O presente trabalho teve como objetivo verificar a viabilidade da utilização da radiação gama como método de conservação do arroz e sua eficiência no controle de uma importante praga de grão armazenado (Sitophilus oryzea L.), e verificar possíveis alterações nas propriedades físicoquímicas e sensoriais destes grãos irradiados durante o armazenamento.

\section{Material e métodos}

\subsection{Matéria-prima}

Foi utilizado arroz (Oryza sativa L.) variedade longo fino tipo 1 cultivado no Sul do País e colhido na safra de 2005, com a presença de aproximadamente $6 \%$ de arroz quebrado. Foram trabalhados arroz em casca e arroz beneficiado (polido).

\subsection{Irradiação das amostras}

A irradiação foi realizada no Centro de Energia Nuclear na Agricultura (CENA/USP), localizado na cidade de Piracicaba, Estado de São Paulo, onde foram empregadas as doses de radiação de 0,5; 1,0; 3,0; e 5,0 kGy, utilizando-se um irradiador de Cobalto 60, modelo Gammacell -220, e a taxa de dose de $0,807 \mathrm{kGy} /$ hora. Foram mantidas nas mesmas condições as amostras controle, sem irradiação.

\subsection{Análises físicas}

Análise da porcentagem de quebra do grão de arroz durante o beneficiamento

As amostras de arroz com casca (100 g) controle, 0,5 e $1,0 \mathrm{kGy}$ foram submetidas ao processo de beneficiamento, sendo utilizado o provador PAZ 1-DT marca Zaccaria, para analisar a porcentagem de grãos de arroz inteiros.

\section{Análise da longevidade e reprodução de} gorgulhos de arroz (Sitophilus oryzae L.)

Os insetos utilizados para a realização desse experimento foram da espécie Sitophilus oryzae L., procedentes de criação normal mantida no laboratório da Seção de Radioentomologia do Cento de Energia Nuclear na Agricultura - CENA/USP, Piracicaba, SP.

O substrato (arroz) foi irradiado com as doses: controle, $0,5 \mathrm{e}$ 1,0 kGy. As embalagens utilizadas eram próprias de arroz comercializado em supermercados, ou seja, sacos plásticos $0,08 \mathrm{~mm}$ de espessura. Foram colocados $200 \mathrm{~g}$ de substrato e 40 insetos em cada embalagem, sendo 3 repetições por tratamento, totalizando 120 insetos por tratamento. Essas embalagens foram mantidas em temperatura ambiente por 40 dias. Para a avaliação, foi realizada a contagem dos insetos ao final do período.

Para a realização da segunda análise, foi utilizado um substrato (arroz) que estava infestado a quatro meses e, antes da irradiação com doses de 0,5 e 1,0 kGy, foram retirados os insetos adultos. O mesmo procedimento foi feito com o controle. Foram, então, acondicionados em sacos plásticos próprios de arroz do comércio com 3 repetições por tratamento e armazenados por 40 dias. Para a avaliação, foi realizada a contagem dos insetos ao final do período. 


\subsection{Análises químicas}

\section{Composição centesimal}

As análises químicas de teor de umidade, proteína bruta, extrato etéreo e de cinza foram realizadas de acordo com a metodologia indicada pela Association of Official Analytical Chemists - AOAC (2006).

\section{Conteúdo de amilose aparente}

O conteúdo de amilose aparente dos grãos de arroz foi determinado usando-se a metodologia ISO 6647 (International Organization for Standardization, 1987).

\section{Propriedades de pasta dos amidos}

As propriedades de pasta de arroz moído foram avaliadas em aparelho Rapid Visco Analyser (RVA), série 4, da Newport Scientific, na concentração de 3,0 g/25 mL de água. Para o cálculo desta concentração, foram efetuadas correções na quantidade de amostra e na quantidade de água adicionada, de acordo com a tabela fornecida pelo fabricante (Newport Scientific, 1998), tomando-se como base o teor de umidade de $14 \%$, para se obter peso seco de 3,0 g. Foi utilizada a programação Std 2 (Standard Analysis 2) do software Thermocline for Windows, versão 2.2, para proceder à avaliação.

\subsection{Análise sensorial}

Foram selecionados aleatoriamente 40 provadores não treinados, consumidores de arroz, dentre uma população de adultos saudáveis (18 a 50 anos), de ambos os sexos.

Realizaram-se testes hedônicos para as características de arroz cru aparência e cor e para arroz cozido aparência, aroma, textura, cor e sabor. Os provadores avaliaram sensorialmente o produto de acordo com metodologia proposta por Dutcosky (1996), através do programa Compusense five (COMPUSENSE INC. 1986-1998). As amostras cozidas foram preparadas com água destilada, óleo de soja e $1 \%$ de $\mathrm{NaCl}$. O teste foi realizado com o aval do Comitê de ética em pesquisa com seres humanos.

No laboratório de análise sensorial com cabines individuais, os provadores receberam as amostras servidas em pratos brancos. Foram apresentadas cinco amostras, uma para cada tratamento: controle, 0,5, 1,0, 3,0 e 5,0 kGy, codificadas com números de 3 dígitos escolhidos de forma aleatória pelo programa Compusense five. Foi solicitado aos provadores que analisassem cada uma das amostras, usando uma escala feita para esse propósito, com nove pontos. Os resultados foram avaliados através de Análise de Variância (ANOVA) e teste de Tukey.

\subsection{Análise instrumental da cor}

As avaliações da cor do arroz foram realizadas utilizando-se colorímetro Minolta CR -200. Os resultados foram expressos em valor $\mathrm{L}$ (luminosidade), que varia do negro $(\mathrm{L}=0)$ ao branco $(\mathrm{L}=100)$; valor $\mathrm{a}^{*}$, que caracteriza coloração na região do vermelho $(+a)$ ao verde (-a); e valor $b^{\star}$, que indica coloração no intervalo do amarelo (+b) ao azul (-b). O Croma, relação entre os valores de $\mathrm{a}^{\star} \mathrm{e} \mathrm{b}^{\star}$, no qual se obtém a saturação da cor da amostra e o ângulo de cor, ângulo formado entre $\mathrm{a}^{\star} \mathrm{e} \mathrm{b}^{*}$, indicando a cor real do objeto, foram calculados segundo Minolta (1997).

\subsection{Análise estatística}

Os dados obtidos após o processamento analítico das amostras foram submetidos à análise de variância (ANOVA). Para verificar quais tratamentos diferiram, foi aplicado o teste de Tukey (Teste teste $T$ de mínima diferença estatística) para realizar comparações pareadas das médias dos tratamentos, estabelecendo-se o nível mínimo de significância de 5\% ( $\mathrm{p} \leq 0,05)$. Utilizou-se software SAS Institute (SAS INSTITUTE,1999).

\section{Resultados e discussão}

\subsection{Análise porcentagem de quebra do grão de arroz e renda base durante o beneficiamento}

A Tabela 1 apresenta os resultados da porcentagem de grãos inteiros de arroz após processo de beneficiamento.

$\mathrm{Na}$ Tabela 1, verifica-se que a radiação gama não afetou a quebra do grão de arroz durante o processo de beneficiamento, sendo que, entre as doses e o controle, não houve diferença significativa $(\mathrm{p}<0,05)$.

A finalidade básica da retirada de partes do arroz no beneficiamento é permitir maior tempo de prateleira, aliada ao melhor aspecto do produto, que se destina ao consumo humano. Vários fatores podem alterar o resultado final do beneficiamento do arroz, um deles é a irradiação.

A renda do beneficiamento, ou seja, o percentual de arroz beneficiado é um dos mais importantes critérios da qualidade do arroz. A preferência é pelo produto com menor quantidade de grãos quebrados, pois o arroz, contendo misturas de grãos quebrados, resulta em cozimento desuniforme, aspecto pouco atrativo ao consumidor e é economicamente indesejável. (PEREIRA, 1996). O fato da irradiação não ter alterado esse índice (Tabela 1) é de importância para que o seu emprego possa ser implementado.

Assim, os fatores a serem considerados no julgamento da qualidade do arroz são muitos e incluem tamanho do grão, aspecto externo e incidência de danos (WEBB, 1985). Esses fatores não foram afetados no arroz irradiado beneficiado, já que não apresentou diferença estatística na quebra dos grãos de arroz, não havendo aumento na incidência de defeitos.

Nas amostras de arroz deste experimento, tanto o irradiado com as doses de 0,5 e 1,0 kGy e o controle, foi obtido resultado

Tabela 1. Média da porcentagem de grãos de arroz inteiros não irradiados e irradiados com doses de 0,5 e 1,0 kGy após o beneficiamento.

\begin{tabular}{cc}
\hline Tratamentos & Grãos inteiros (\%) \\
\hline Controle & $90,9 \pm 0,1^{1 \mathrm{a} 2}$ \\
$0,5 \mathrm{kGy}$ & $90,8 \pm 0,1^{\mathrm{a}}$ \\
$1,0 \mathrm{kGy}$ & $90,9 \pm 0,1^{\mathrm{a}}$ \\
\hline
\end{tabular}

${ }^{1}$ Média \pm desvio padrão; ${ }^{2}$ médias seguidas de letras iguais, nas colunas, não diferem entre si pelo teste de Tukey, ao nível de significância de $5 \%(\mathrm{p}<0,05)$. 
da renda-base de $66 \%$. Isso resultou da retirada da casca e farelo, que somaram 29 e $5 \mathrm{~g}$ quirera, restando $66 \mathrm{~g}$ de arroz inteiro e quebrado. A porcentagem de grãos inteiros foi de $60 \%$, o resultado de quebra do arroz foi de $6 \%$, tendo $94,0 \mathrm{~g}$ de grãos inteiros em $100 \mathrm{~g}$.

\subsection{Análise da longevidade e reprodução de gorgulhos de arroz (Sitophilus oryzae L.)}

A Tabela 2 apresenta o desenvolvimento de Sitophilus oryzae L., por dose e números que permaneceram vivos durante o armazenamento após a irradiação do substrato.

Os gorgulhos de arroz utilizados neste experimento (Sitophilus oryzae L.) possuem elevado potencial biótico, podendo infestar os produtos tanto no campo como nos depósitos (ARTHUR et al., 1990) e podem se desenvolver mesmo após a irradiação com dose de $0,5 \mathrm{kGy}$, como pode ser observado nos resultados apresentados na Tabela 2 .

A Tabela 3 apresenta o desenvolvimento de Sitophilus oryzae L., por dose e números de nascimento durante o armazenamento após a irradiação do substrato.

Segundo Parizzi (1993), vários fatores podem levar à perda de qualidade do arroz, muitos resultam principalmente do ataque de insetos e fungos. $\mathrm{O}$ inseto testado apresenta alta capacidade de infestação em grãos não tratados (Tabelas 2 e 3).

Com os resultados obtidos nas avaliações, pode ser verificado que a irradiação causou efeito negativo no desenvolvimento dos insetos que foram colocados no arroz irradiado. No final do período de 40 dias de armazenamento, apenas 13 e 4 insetos permaneceram vivos nos tratamentos com as doses de 0,5 e 1,0 kGy, respectivamente. Já no controle, havia 76 insetos se desenvolvendo no substrato.

Na Tabela 3, pode ser observado também que na dose controle houve infestação. Porém, no substrato irradiado, não houve nascimento dos gorgulhos, apenas 3 insetos foram encontrados na dose de 0,5 kGy ao final de 40 dias de armazenamento.

Hu et al. (1985) apud Fontes e Arthur (1994) verificaram os efeitos da radiação gama sobre Tribolium castaneum (Herbst.) e observaram que, com três semanas após a irradiação, não houve

Tabela 2. Número de insetos vivos Sitophilus oryzae L., que foram colocados no substrato (arroz) após a irradiação e controle.

\begin{tabular}{cc}
\hline Tratamentos (kGy) & Insetos vivos (unidades) \\
\hline 0 & $76^{1}$ \\
0,5 & 13 \\
1,0 & 4 \\
\hline
\end{tabular}

${ }^{1}$ Soma do número de insetos vivos nas 3 repetições.

Tabela 3. Número de insetos que emergiram Sitophilus oryzae L., no substrato (arroz) após a irradiação e controle.

\begin{tabular}{cc}
\hline Tratamentos $(\mathrm{kGy})$ & Insetos que emergiram (unidades) \\
\hline 0 & $137^{1}$ \\
0,5 & 3 \\
1,0 & 0 \\
\hline
\end{tabular}

${ }^{1}$ Soma do número de insetos que emergiram nas 3 repetições. sobrevivência de pupas e adultos com doses de 200-600 Gy, e todos os que receberam dose de $100 \mathrm{~Gy}$ estavam mortos. A dose de 41 Gy matou 100\% de ovos e larvas, indicando que esse inseto é menos resistente à irradiação que o Sitophilus oryzae L.

Os resultados da Tabela 3 são contrários aos verificados por Wiendl et al. (1974), que constataram menor longevidade nos insetos adultos de Sitophilus zeamais que se alimentaram de arroz irradiado, mas a dose de $20 \mathrm{krad}$ causou aumento significativo na reprodução.

Segundo Groppo (1988), devido ao poder residual nulo das radiações, pode ocorrer a reinfestação do produto. Isso não foi visto neste experimento, pois, com o aumento das doses, o número de insetos que foi colocado no substrato após a irradiação (reinfestação forçada) diminuiu significativamente. Conclui-se que algumas variações podem ter ocorrido nesta fase, como idade do ciclo evolutivo do inseto e condições climáticas do armazenamento diferentes do estudo referido, fatores importantes que contribuem para que ocorram discrepâncias.

\subsection{Composição centesimal}

Os resultados referentes à composição centesimal do arroz analisada em matéria fresca, em grãos irradiados e não irradiados, são mostrados na Tabela 4 .

A irradiação não alterou de maneira significativa a composição centesimal (Tabela 4) das amostras analisadas, com exceção do teor de umidade para o arroz cozido.

Conforme pode ser visualizado na Tabela 4, os valores médios de umidade total variaram de 10,33 a $10,97 \%$ para as amostras de arroz cru e de 67,49 a 71,64\% nas amostras de arroz cozido. Os teores de umidade encontrados são próximos aos valores encontrados na literatura para o arroz cru, os quais variaram entre 12 e 13,2\% e para o arroz cozido 61,6 e 73,48\% (IBGE, 1999; UNICAMP, 2006; USP, 2005).

Tabela 4. Médias obtidas pelo controle e grãos irradiados com doses de 0,5 e 1,0 kGy para a composição centesimal do arroz cru e cozido (Base fresca) comparados pelo teste de Tukey.

\begin{tabular}{|c|c|c|c|c|c|}
\hline Tratamentos & $\begin{array}{l}\text { Umidade } \\
(\%)\end{array}$ & $\begin{array}{c}\text { Cinza } \\
(\%)\end{array}$ & $\begin{array}{c}\text { Extrato } \\
\text { etéreo (\%) }\end{array}$ & $\begin{array}{c}\text { Proteína } \\
(\%)\end{array}$ & $\begin{array}{c}\mathrm{CHO} \\
(\%)\end{array}$ \\
\hline \multicolumn{6}{|c|}{ Arroz cru } \\
\hline Controle & $10,97 \pm 0,5^{1 \mathrm{a} 2}$ & $0,34 \pm 0,0^{\mathrm{a}}$ & $0,50 \pm 0,0^{\mathrm{a}}$ & $8,83 \pm 0,2^{\mathrm{a}}$ & 79,85 \\
\hline 0,5 kGy & $10,93 \pm 0,2^{\mathrm{a}}$ & $0,38 \pm 0,0^{a}$ & $0,40 \pm 0,0^{\mathrm{a}}$ & $7,94 \pm 1,1^{\mathrm{a}}$ & 80,74 \\
\hline $1,0 \mathrm{kGy}$ & $10,33 \pm 0,3^{\mathrm{a}}$ & $0,35 \pm 0,1^{\mathrm{a}}$ & $0,12 \pm 0,0^{\mathrm{a}}$ & $7,50 \pm 0,3^{\mathrm{a}}$ & 81,8 \\
\hline 3,0 kGy & $10,74 \pm 0,4^{\mathrm{a}}$ & $0,40 \pm 0,1^{\mathrm{a}}$ & $0,20 \pm 0,0^{\mathrm{a}}$ & $7,61 \pm 0,2^{\mathrm{a}}$ & 81,25 \\
\hline $5,0 \mathrm{kGy}$ & $10,68 \pm 0,5^{\mathrm{a}}$ & $0,45 \pm 0,0^{\mathrm{a}}$ & $0,60 \pm 0,0^{\mathrm{a}}$ & $8,72 \pm 0,2^{\mathrm{a}}$ & 80,14 \\
\hline \multicolumn{6}{|c|}{ Arroz cozido } \\
\hline Controle & $69,96 \pm 0,1^{\mathrm{b}}$ & $0,14 \pm 0,0^{\mathrm{a}}$ & $0,06 \pm 0,0^{\mathrm{a}}$ & $2,34 \pm 0,2^{\mathrm{a}}$ & 27,56 \\
\hline 0,5 kGy & $68,55 \pm 0,1^{c}$ & $0,14 \pm 0,0^{\mathrm{a}}$ & $0,01 \pm 0,0^{\mathrm{a}}$ & $2,68 \pm 0,2^{\mathrm{a}}$ & 28,63 \\
\hline $1,0 \mathrm{kGy}$ & $67,49 \pm 0,1^{\mathrm{d}}$ & $0,14 \pm 0,0^{\mathrm{a}}$ & $0,06 \pm 0,0^{\mathrm{a}}$ & $2,92 \pm 0,4^{\mathrm{a}}$ & 29,45 \\
\hline 3,0 kGy & $71,64 \pm 0,0^{\mathrm{a}}$ & $0,14 \pm 0,0^{\mathrm{a}}$ & $0,06 \pm 0,0^{\mathrm{a}}$ & $2,57 \pm 0,2^{\mathrm{a}}$ & 25,65 \\
\hline 5,0 kGy & $69,85 \pm 0,1^{\mathrm{b}}$ & $0,14 \pm 0,0^{\mathrm{a}}$ & $0,03 \pm 0,0^{\mathrm{a}}$ & $2,84 \pm 0,2^{\mathrm{a}}$ & 27,17 \\
\hline
\end{tabular}


Os valores médios de cinza das amostras analisadas neste trabalho variaram de 0,34 a $0,45 \%$ no arroz cru e $0,14 \%$ para todas as amostras de arroz cozido, sendo esses valores correspondentes aos valores observados para arroz cru e cozido, 0,5, 0,1 e 0,3\%, respectivamente (IBGE, 1999; UNICAMP, 2006; USP, 2005). As amostras não irradiadas e irradiadas não diferiram entre si quanto ao teor de cinza, demonstrando que a irradiação não teve influência sobre o teor de cinza do arroz analisado.

Os teores de lipídios variaram de 0,12 a 0,60\%, no arroz cru, e de 0,01 a $0,06 \%$, no arroz cozido, estando esses valores similares aos encontrados na literatura para o arroz cru, sendo de 0,3 a $0,9 \%$ e inferiores de 0,2 a $0,6 \%$ para o arroz cozido (IBGE, 1999; MAIA et al., 1999; UNICAMP, 2006; USP, 2005). Quanto às amostras irradiadas e não irradiadas, não houve diferença entre os teores de lipídios.

Quanto à proteína presente nas amostras analisadas, os níveis variaram entre 7,50 e 8,72\% e entre 2,34 e 2,92\% no arroz crue cozido, respectivamente. Os valores médios de proteínas observados estão semelhantes aos teores encontrados na literatura, os quais variaram de 6,73 a 7,2\% para arroz cru e de 2,3 a 2,5\% para arroz cozido (IBGE, 1999; UNICAMP, 2006; USP, 2005).

Os valores médios de carboidratos encontrados nas amostras analisadas variaram de 79,85 a $81,25 \%$ para o arroz cru e de 25,65 a $29,45 \%$ para o arroz cozido. Verificamos, assim, que a irradiação não alterou o teor de carboidratos do arroz analisado, pois os valores encontrados são semelhantes aos propostos por IBGE (1999), UNICAMP (2006) e USP (2005).

Zuleta et al. (2006), estudando a composição química de arroz irradiado, também não encontraram diferença na composição do carboidratos totais.

\subsection{Conteúdo de amilose aparente nos amidos de arroz}

Na Tabela 5, podem ser observados os valores de amilose aparente nos amidos de arroz irradiado e não irradiado.

Não houve diferença significativa entre as amostras estudadas, embora pareça haver tendência à redução com as doses mais elevadas, pois foi verificado que, com 3,0 e 5,0 kGy, os conteúdos de amilose reduziram em 1 e $6 \%$, respectivamente. Nas análises realizadas por Yu e Wang (2007), para as mesmas doses, houve uma redução de 2,9 e 6,6\% nos teores de amilose do arroz irradiado, sendo tal diminuição explicada pela quebra ou divisão das cadeias longas de amilopectina causadas pela irradiação. Na irradiação com 10 kGy, chegou a 12,2\%.

Tabela 5. Médias obtidas para arroz controle e irradiados com doses 0,5; 1,0; 3,0; e 5,0 kGy) e teste de Tukey para teor de amilose aparente do amido arroz.

\begin{tabular}{cl}
\hline Tratamentos & Amilose (\%) \\
\hline & Arroz cru \\
Controle & $18,4 \pm 0,1^{1 \mathrm{a} 2}$ \\
$0,5 \mathrm{kGy}$ & $18,9 \pm 0,4^{\mathrm{a}}$ \\
$1,0 \mathrm{kGy}$ & $18,9 \pm 0,2^{\mathrm{a}}$ \\
$3,0 \mathrm{kGy}$ & $18,2 \pm 0,4^{\mathrm{a}}$ \\
$5,0 \mathrm{kGy}$ & $17,3 \pm 0,04^{\mathrm{a}}$ \\
\hline
\end{tabular}

${ }^{1}$ Média \pm desvio padrão; $\mathrm{e}^{2}$ médias seguidas de letras iguais, nas colunas, não diferem entre si pelo teste de Tukey, ao nível de significância de $5 \%(\mathrm{p} \leq 0,05)$.
Bao, Ao e Jane (2005) reportaram a fragmentação da amilopectina com a irradiação de arroz e decréscimo do peso molecular. A quebra da cadeia de amilopectina ocorreu nas regiões amorfas, tendo pouco efeito nas regiões cristalinas dos grânulos de amido, especialmente em baixa dose de irradiação,

Segundo Gonzalez, Livore e Pons (2007), o arroz com maior teor de amilose e com amilopectina de cadeia mais longa, tende a apresentar propriedades de cozimento com textura mais dura. $\mathrm{O}$ arroz com conteúdo mais baixo de amilose e com amilopectina de cadeia mais curta tende a apresentar textura mais macia após o cozimento. Portanto, a redução do percentual de amilose (Tabela 5) pode contribuir para uma textura mais macia do grão após cozimento.

\subsection{Propriedades de pasta dos amidos}

As propriedades de pasta dos grãos de arroz controle e tratados por irradiação são apresentadas na Tabela 6 .

A irradiação alterou significativamente todas as características de pasta do amido de arroz (Tabela 6). Este resultado evidencia quebra nas cadeias de amido e por consequência, mudanças na estrutura do amido e em suas funcionalidades.

A temperatura de pasta indica a temperatura mínima necessária para o cozimento de uma determinada amostra, o que pode ter implicações na estabilidade de outros componentes presentes em uma formulação e também indica a energia a ser consumida neste processo (NEWPORT, 1998). Assim, variações nesse parâmetro podem alterar a qualidade dos alimentos bem como os custos com a energia gasta nos processos. No presente estudo, pode-se observar tendência à redução da temperatura de pasta nas maiores doses de irradiação (Tabela 6). Foi verificado que não houve diferença estatística entre o controle e as doses 0,5 e 1,0 kGy, mas as doses de 3,0 e 5,0 kGy foram estatisticamente diferentes do controle e de $0,5 \mathrm{kGy}$.

O aumento das doses de irradiação promoveu diminuição gradual (de 5,9 minutos para 5,2 minutos) no tempo para ocorrência do pico. Isto pode ser explicado pela redução da temperatura de pasta.

Houve redução dos valores de viscosidade máxima com a irradiação em até dois terços do valor obtido para o amido natural. Os valores de viscosidade final das pastas de amido acompanharam a tendência de redução gradual com a elevação das doses de irradiação do produto.

Sung (2005), estudando o efeito da irradiação nas propriedades de pasta do arroz, observou que a dose de 1,0 kGy modificou a microestrutura do amido e gerou a redução da viscosidade da pasta. Segundo esse autor, a redução de viscosidade do arroz, como observada durante seu armazenamento, é interessante do ponto de vista culinário. Isso pode ser a razão da preferência da indústria por arroz mais velho para fazer produtos derivados de arroz. $\mathrm{O}$ arroz velho, armazenado por um ano, é menos pegajoso no cozimento.

De acordo com Yu e Wang (2007), o amido com teor de amilose menor apresenta valores mais elevados de viscosidade máxima por ocorrer maior inchamento dos grânulos, diminuin- 
Tabela 6. Propriedades de pasta das amostras de farinha de arroz não irradiadas e irradiadas com doses de 0,5; 1,0; 3,0 e 5,0 kGy.

\begin{tabular}{|c|c|c|c|c|c|c|}
\hline $\begin{array}{l}\text { Doses } \\
(\mathrm{kGy})\end{array}$ & $\begin{array}{c}\text { Temperatura de } \\
\text { pasta }\left({ }^{\circ} \mathrm{C}\right)\end{array}$ & $\begin{array}{l}\text { Pico } \\
\text { (RVU) }\end{array}$ & $\begin{array}{l}\text { Quebra } \\
\text { (RVU) }\end{array}$ & $\begin{array}{c}\text { Viscosidade final } \\
\text { (RVU) }\end{array}$ & $\begin{array}{c}\text { Tendência à } \\
\text { trogradação (RVU) }\end{array}$ & $\begin{array}{c}\text { Tempo de pico } \\
\text { (minutos) }\end{array}$ \\
\hline 0,0 & $91 \pm 1,84^{1 \text { a } 2}$ & $201 \pm 0^{\mathrm{a}}$ & $22 \pm 1,5^{c}$ & $369 \pm 0^{\mathrm{a}}$ & $168 \pm 0,5^{\mathrm{a}}$ & $5,9 \pm 0^{\mathrm{a}}$ \\
\hline 0,5 & $91 \pm 1,66^{a}$ & $175 \pm 0,3^{\mathrm{b}}$ & $31 \pm 3,7^{b}$ & $292 \pm 4,9^{b}$ & $122 \pm 1,1^{b}$ & $5,7 \pm 0,03^{b}$ \\
\hline 3,0 & $89 \pm 0,02^{b}$ & $96 \pm 1,7^{\mathrm{d}}$ & $39 \pm 1,0^{a}$ & $107 \pm 1,2^{\mathrm{d}}$ & $11 \pm 0,5^{\mathrm{d}}$ & $5,4 \pm 0,04^{\mathrm{d}}$ \\
\hline 5,0 & $88 \pm 1,28^{\mathrm{b}}$ & $61 \pm 0,3^{e}$ & $31 \pm 0^{\mathrm{b}}$ & $57 \pm 0,9^{\mathrm{e}}$ & $1 \pm 5,21^{\mathrm{e}}$ & $5,2 \pm 0^{\mathrm{e}}$ \\
\hline
\end{tabular}

${ }^{1}$ Média \pm desvio padrão; $\mathrm{e}^{2}$ médias seguidas de letras iguais nas colunas, não diferem entre si pelo teste de Tukey, em nível de significância de $5 \%$ ( $\mathrm{p} \leq 0,05$ ).

do consequentemente, a água livre da suspensão amido/água. Pode-se inferir disto que o pico de viscosidade está positivamente correlacionado com o poder de inchamento dos grânulos.

Zuleta et al. (2006), estudando três diferentes cultivares de arroz com conteúdo de 25, 19 e 5\% de amilose, observaram que a viscosidade do gel diminuiu significativamente com as doses de 1,5 e 3,0 kGy, nas cultivares com 19 e 5\%. Embora essa correlação exista na literatura, no presente trabalho a variação da viscosidade máxima não pode ser atribuída à amilose, pois a irradiação não alterou significativamente o conteúdo desta (Tabela 5). A redução da viscosidade possivelmente seja devido à redução do peso molecular das macromoléculas que compõem o amido.

Os grãos de arroz irradiados apresentaram grânulos de amido mais susceptíveis à ruptura que os não irradiados (quebra de viscosidade), quando submetidos à agitação em temperaturas elevadas. Isto significa que os grânulos de amido dos grãos tornam-se menos estáveis ao cisalhamento.

O parâmetro retrogradação é frequentemente usado como indicador da firmeza de arroz cozido. Valores mais altos indicam textura mais firme (WU et al., 2002). A tendência à retrogradação do amido dos grãos tratados no presente estudo se tornou menos acentuada se comparada com a do amido de grãos de arroz não tratados. Tal resultado indica que este tipo de processamento abranda a textura do arroz cozido. Isto também é um fator positivo para arroz cozido e armazenado sob temperaturas mais baixas (refrigeração ou congelamento), pois, quanto menos intensa a retrogradação, menos problemas com a textura do produto. A retrogradação pode conduzir ao aumento de dureza dos grãos devido à recristalização das macromoléculas do amido.

A retrogradação acontece mais rapidamente em amido de arroz com alto conteúdo de amilose e durante o armazenamento à baixa temperatura (ZULETA et al., 2006).

\subsection{Análise sensorial}

Na Tabela 7, podem ser observadas as médias da avaliação dos atributos sensoriais (aparência e cor) nos grãos de arroz cru tratado e não tratado por irradiação.

Observa-se, na Tabela 7, que o processo de irradiação influiu nos parâmetros de aparência e cor para o arroz cru nas doses de 3,0 e 5,0 kGy.

As amostras de arroz controle e com dose de 0,5 e 1,0 kGy obtiveram médias acima de 6 , e não apresentaram diferença sig-
Tabela 7. Média das notas conferidas aos atributos avaliados nos grãos de arroz cru tratados por irradiação e controle.

\begin{tabular}{ccl}
\hline Atributos & Tratamentos & \multicolumn{1}{c}{ Médias } \\
\hline Aparência & Controle & $6,88 \pm 2,0^{1 \mathrm{a} 2}$ \\
& $0,5 \mathrm{kGy}$ & $6,75 \pm 1,9^{\mathrm{a}}$ \\
$1,0 \mathrm{kGy}$ & $6,65 \pm 1,8^{\mathrm{ab}}$ \\
& $3,0 \mathrm{kGy}$ & $5,95 \pm 1,9^{\mathrm{b}}$ \\
& $5,0 \mathrm{kGy}$ & $5,23 \pm 2,1^{\mathrm{c}}$ \\
Cor & Controle & $7,03 \pm 1,8^{\mathrm{a}}$ \\
& $0,5 \mathrm{kGy}$ & $6,38 \pm 1,9^{\mathrm{a}}$ \\
& $1,0 \mathrm{kGy}$ & $6,50 \pm 1,8^{\mathrm{a}}$ \\
& $3,0 \mathrm{kGy}$ & $5,40 \pm 1,7^{\mathrm{b}}$ \\
& $5,0 \mathrm{kGy}$ & $4,75 \pm 1,7^{\mathrm{b}}$ \\
\hline
\end{tabular}

${ }^{1}$ Média \pm desvio padrão; $\mathrm{e}^{2}$ médias seguidas de letras iguais nas colunas não diferem entre si pelo teste de Tukey, em nível de significância de $5 \%(\mathrm{p} \leq 0,05)$.

nificativa em nível de p < 0,05, já as doses de 3,0 e 5,0 kGy foram estatisticamente diferentes das demais doses e o controle.

$\mathrm{O}$ mesmo pode ser observado com relação à cor das amostras do arroz cru, o controle e as doses de 0,5 e 1,0 kGy não apresentaram diferença estatística e a média apresentou-se entre 6,50 e 7,03. Com as doses de 3,0 e 5,0 kGy houve diferença estatística, sendo que a dose de 5,0 kGy não alcançou o limite de aceitação (média 5) para o parâmetro cor da amostra crua.

Na Tabela 8, podem ser observadas as médias da avaliação dos atributos sensoriais (aparência, aroma, textura, cor e sabor) do arroz cozido tratado e não tratado por irradiação.

Observa-se, na Tabela 8, que o processo de irradiação influiu nos parâmetros de aparência, aroma, textura, cor e sabor do arroz cozido. A textura, a cor e o sabor obtiveram médias maiores na dose de 1,0 kGy e foram estatisticamente diferentes do controle e das demais doses de irradiação (0,5; 3; e 5 kGy).

Sirisoontaralak e Noomhorn (2006) observaram que a satisfação dos provadores com a aparência, cor, odor, textura e sabor das amostras de arroz cozido diminuíram com o aumento das doses de irradiação. Neste trabalho, verificamos que a dose de 5,0 kGy obtive as menores médias, sendo que causou menor satisfação aos provadores em todos os parâmetros analisados, mas, discordando do trabalho citado, a média da dose de 1,0 kGy superou a média do arroz cozido não irradiado.

Nas Tabelas 9-13, são apresentadas as porcentagens das diferentes notas apresentadas pelos provadores para a aparência, aroma, textura, cor e sabor.

Foi detectada diferença estatística significativa $(\mathrm{p}<0,05)$ apenas no tratamento de 5,0 kGy quanto à aparência (Tabela 9), 
sendo que, nesse caso, $67,5,72,5$ e $82,5 \%$ dos provadores declararam gostar (ligeiramente a muitíssimo) da aparência das amostras de arroz não irradiada e irradiadas com doses de 0,5 e $1,0 \mathrm{kGy}$, respectivamente.

Lee (2007) reporta que, embora a irradiação possa melhorar a vida-de-prateleira do arroz cozido, sua aplicação pode ser limitada porque os consumidores são sensíveis às mudanças das propriedades sensoriais do arroz cozido como sabor, textura e coloração depois da irradiação, isso pode ter ocorrido na dose mais alta de $5 \mathrm{kGy}$, que, neste trabalho, obteve a média de 5,03, porém em doses mais baixas, efetivas para o controle de praga, apresentou ótimos resultados.

As amostras de arroz irradiadas com doses de 3,0 e 5,0 kGy diferiram estatisticamente $(\mathrm{p}<0,05)$ das demais doses $(0,5$ e 1,0 kGy) e do controle, sendo que $67,5 \%$ e $72,5 \%$ dos provadores declararam gostar (ligeiramente a muitíssimo) do aroma das amostras irradiadas com 0,5 e 1,0 kGy (Tabela 10). Nesse caso, 57,5\% dos provadores declararam não gostar (ligeiramente a muitíssimo) do aroma da amostras irradiadas com dose de 5,0 kGy.

A irradiação contribuiu com as mudanças da cor e aroma do arroz cozido. Dose satisfatória máxima a ser utilizada para não afetar o aroma seria de $0,5 \mathrm{kGy}$, segundo Sirisoontaralak e Noomhorn (2006). Neste mesmo estudo, os provadores descobriram claramente mudanças no aroma do arroz em baixas doses, entretanto, como pode ser constatado pelos resultados

Tabela 8. Média das notas conferidas aos atributos avaliados nos grãos de arroz cozido tratados por irradiação e controle.

\begin{tabular}{|c|c|c|}
\hline Atributos & Tratamentos & Médias \\
\hline \multirow[t]{5}{*}{ Aparência } & Controle & $6,20 \pm 2,0^{1 \mathrm{a} 2}$ \\
\hline & 0,5 kGy & $6,15 \pm 1,9^{\mathrm{a}}$ \\
\hline & 1,0 kGy & $6,90 \pm 1,3^{\mathrm{a}}$ \\
\hline & 3,0 kGy & $6,03 \pm 1,6^{\mathrm{a}}$ \\
\hline & 5,0 kGy & $5,03 \pm 1,9^{b}$ \\
\hline \multirow[t]{5}{*}{ Aroma } & Controle & $6,08 \pm 1,9^{\mathrm{ab}}$ \\
\hline & 0,5 kGy & $6,63 \pm 1,6^{\mathrm{a}}$ \\
\hline & 1,0 kGy & $6,60 \pm 1,5^{\mathrm{a}}$ \\
\hline & 3,0 kGy & $5,73 \pm 2,1^{\mathrm{b}}$ \\
\hline & $5,0 \mathrm{kGy}$ & $4,18 \pm 2,0^{c}$ \\
\hline \multirow[t]{5}{*}{ Textura } & Controle & $5,60 \pm 1,9^{b}$ \\
\hline & 0,5 kGy & $5,83 \pm 1,8^{\mathrm{b}}$ \\
\hline & $1,0 \mathrm{kGy}$ & $7,15 \pm 1,8^{\mathrm{a}}$ \\
\hline & 3,0 kGy & $6,03 \pm 2,0^{\mathrm{b}}$ \\
\hline & $5,0 \mathrm{kGy}$ & $4,73 \pm 2,1^{\mathrm{c}}$ \\
\hline \multirow[t]{5}{*}{ Cor } & Controle & $5,68 \pm 2,0^{\mathrm{b}}$ \\
\hline & 0,5 kGy & $6,13 \pm 1,8^{\mathrm{b}}$ \\
\hline & 1,0 kGy & $7,75 \pm 1,5^{\mathrm{a}}$ \\
\hline & 3,0 kGy & $6,38 \pm 1,7^{b}$ \\
\hline & $5,0 \mathrm{kGy}$ & $4,78 \pm 1,8^{\mathrm{c}}$ \\
\hline \multirow[t]{5}{*}{ Sabor } & Controle & $6,08 \pm 2,0^{b}$ \\
\hline & 0,5 kGy & $5,90 \pm 1,5^{\mathrm{b}}$ \\
\hline & 1,0 kGy & $7,20 \pm 1,5^{\mathrm{a}}$ \\
\hline & 3,0 kGy & $5,33 \pm 1,9^{\mathrm{bc}}$ \\
\hline & $5,0 \mathrm{kGy}$ & $4,48 \pm 1,9^{c}$ \\
\hline
\end{tabular}

${ }^{1}$ Média \pm desvio padrão; $\mathrm{e}^{2}$ médias seguidas de letras iguais nas colunas não diferem entre si pelo teste de Tukey, em nível de significância de $5 \%(\mathrm{p}<0,05)$. apresentados nas Tabelas de 1 a 7 , pode-se recomendar a dose de $1 \mathrm{kGy}$ para emprego em arroz.

Os provadores declararam que as doses mais altas utilizadas $(3,0$ e 5,0 kGy) mais prejudicaram o aroma do arroz cozido. A dose de 5,0 kGy não atingiu a média de aceitação (média 5), sendo a menor média encontrada em todos os atributos avaliados.

A amostra de arroz irradiada com dose de 1,0 kGy obteve a maior média, de 7,15, e apresentou diferença estatística $(p<0,05)$ das demais doses e do controle, sendo que $82,5 \%$ dos provadores declararam gostar (ligeiramente a muitíssimo) da textura da amostra irradiada com 1,0 kGy (Tabela 11).

As amostras controle e as irradiadas com 0,5 e 3 kGy não diferiram estatisticamente, sendo que 50 e $60 \%$ dos provadores declararam gostar (ligeiramente a muitíssimo) da textura da amostra não irradiada e irradiadas com doses de 0,5 e 3,0 kGy. A amostra irradiada com a dose de 5,0 kGy, não alcançou o limite de aceitação (média 5), sendo que $62,5 \%$ dos provadores declararam desgostei (ligeiramente a muitíssimo) e foram indiferentes para a textura do arroz, não apresentando diferença estatística somente para a amostra controle.

Sirisoontaralak e Noomhorn (2006) observaram que a textura do arroz foi significativamente mais macia com a dose acima de $0,5 \mathrm{kGy}$. Isso pode ser atribuído à maior absorção de água durante o cozimento, devido a irradiação modificar os grâ-

Tabela 9. Aceitabilidade (\%) para aparência do arroz branco (Oryza sativa L.) irradiado e não irradiado.

\begin{tabular}{lrrrrr}
\hline & \multicolumn{5}{c}{ Tratamentos } \\
\hline \multicolumn{1}{c}{ Escala hedônica } & Controle & $\begin{array}{c}0,5 \\
\mathrm{kGy}\end{array}$ & $\begin{array}{c}1,0 \\
\mathrm{kGy}\end{array}$ & $\begin{array}{c}3,0 \\
\mathrm{kGy}\end{array}$ & $\begin{array}{c}5,0 \\
\mathrm{kGy}\end{array}$ \\
\hline Desgostei muitíssimo & 2,5 & 0,0 & 2,5 & 0,0 & 2,5 \\
Desgostei muito & 0,0 & 5,0 & 0,0 & 2,5 & 7,5 \\
Desgostei moderadamente & 5,0 & 10,0 & 0,0 & 2,5 & 5,0 \\
Desgostei ligeiramente & 20,0 & 2,5 & 5,0 & 12,5 & 30,0 \\
Indiferente & 5,0 & 10,0 & 10,0 & 20,0 & 17,5 \\
Gostei ligeiramente & 15,0 & 22,5 & 10,0 & 25,0 & 12,5 \\
Gostei moderadamente & 20,0 & 25,0 & 35,0 & 12,5 & 15,0 \\
Gostei muito & 25,0 & 20,0 & 25,0 & 22,5 & 7,5 \\
Gostei muitíssimo & 7,5 & 5,0 & 2,5 & 2,5 & 2,5 \\
\hline
\end{tabular}

Tabela 10. Aceitabilidade (\%) para aroma do arroz branco (Oryza sativa L.) irradiado e não irradiado.

\begin{tabular}{lrrrrr}
\hline & \multicolumn{5}{c}{ Tratamentos } \\
\hline \multicolumn{1}{c}{ Escala hedônica } & Controle & $\begin{array}{c}0,5 \\
\mathrm{kGy}\end{array}$ & $\begin{array}{c}1,0 \\
\mathrm{kGy}\end{array}$ & $\begin{array}{c}3,0 \\
\mathrm{kGy}\end{array}$ & $\begin{array}{c}5,0 \\
\mathrm{kGy}\end{array}$ \\
\hline Desgostei muitíssimo & 0,0 & 0,0 & 0,0 & 2,5 & 10,0 \\
Desgostei muito & 5,0 & 0,0 & 0,0 & 7,5 & 12,5 \\
Desgostei moderadamente & 2,5 & 2,5 & 2,5 & 7,5 & 17,5 \\
Desgostei ligeiramente & 15,0 & 5,0 & 5,0 & 7,5 & 17,5 \\
Indiferente & 22,5 & 25,0 & 20,0 & 17,5 & 17,5 \\
Gostei ligeiramente & 5,0 & 7,5 & 17,5 & 15,0 & 7,5 \\
Gostei moderadamente & 17,5 & 22,5 & 22,5 & 17,5 & 12,5 \\
Gostei muito & 27,5 & 30,0 & 22,5 & 22,5 & 5,0 \\
Gostei muitíssimo & 5,0 & 7,5 & 10,0 & 2,5 & 0,0 \\
\hline
\end{tabular}


nulos de amido, permitindo à água entrar com maior facilidade, como constatado pelos resultados apresentados na Tabela 6 .

Para cor, assim como ocorreu para textura, a amostra de $1,0 \mathrm{kGy}$ apresentou diferença estatística $(\mathrm{p}<0,05)$ das demais amostras irradiadas e controle, sendo que $75 \%$ dos provadores declararam gostar (muito e muitíssimo) da cor da amostra do arroz irradiado com dose de 1,0 kGy.

As amostras controle e irradiadas com doses de 0,5 e 3,0 kGy não apresentaram diferença estatística. A dose de 5,0 kGy obteve a menor média, sendo estatisticamente diferente das demais doses.

Segundo Lee (2007), a intensidade da cor dos alimentos irradiados foi aumentando com o aumento da dose de irradiação, influenciando sua aceitação (Tabelas 7 e 8).

Bao, Ao e Jane (2005) concluíram que a irradiação de arroz para consumo humano deveria ser limitada de 2 a $4 \mathrm{kGy}$, devido ao efeito negativo na cor e aroma do arroz. Pelos dados encontrados, a dose de 5,0 kGy não teve boa aceitação (Tabela 8).

Neste experimento, foi verificado que as doses controle, 0,5 e 1,0 kGy não alteraram significativamente a cor do arroz cru, entretanto, doses acima de 3,0 kGy tiveram efeito negativo na cor do arroz irradiado. Quanto ao arroz cozido, este parâmetro foi alterado, sendo que a dose de 1,0 kGy atingiu a maior média, diferindo significativamente das demais amostras, portanto a cor da amostra irradiada com dose de 1,0 kGy obteve melhor aceitação dos provadores.

A amostra de 1,0 kGy diferiu das demais amostras quanto ao sabor, sendo que $87,5 \%$ dos provadores declararam gostar (ligeiramente a muitíssimo) do sabor do arroz irradiado com a dose de 1,0 kGy (Tabela 12). As amostras controle e irradiadas com 0,5 e 3,0 kGy não diferiram estatisticamente ( $<<0,05)$, sendo que 67,5, 70,0 e 55,0\% dos provadores declararam gostar (ligeiramente) do sabor do arroz não irradiado e irradiado com as doses de 0,5 e 3,0 kGy, respectivamente (Tabela 13).

Para a amostra irradiada com a dose de 5,0 kGy, 70\% dos provadores declararam não gostar (ligeiramente a muitíssimo) e indiferente ao sabor do arroz irradiado com dose de 5,0 kGy.

Segundo Sirisoontaralak e Noomhorn (2006), os provadores consideraram o sabor, a aparência e a cor como parâmetros mais

Tabela 11. Aceitabilidade (\%) para textura do arroz branco (Oryza sativa L.) irradiado e não irradiado.

\begin{tabular}{lrrrrr}
\hline & \multicolumn{5}{c}{ Tratamentos } \\
\hline \multicolumn{1}{c}{ Escala hedônica } & Controle & $\begin{array}{c}0,5 \\
\mathrm{kGy}\end{array}$ & $\begin{array}{c}1,0 \\
\mathrm{kGy}\end{array}$ & $\begin{array}{c}3,0 \\
\mathrm{kGy}\end{array}$ & $\begin{array}{c}5,0 \\
\mathrm{kGy}\end{array}$ \\
\hline Desgostei muitíssimo & 0,0 & 0,0 & 0,0 & 0,0 & 5,0 \\
Desgostei muito & 5,0 & 2,5 & 2,5 & 7,5 & 10,0 \\
Desgostei moderadamente & 7,5 & 12,5 & 5,0 & 5,0 & 20,0 \\
Desgostei ligeiramente & 22,5 & 7,5 & 2,5 & 10,0 & 10,0 \\
Indiferente & 15,0 & 17,5 & 5,0 & 17,5 & 17,5 \\
Gostei ligeiramente & 10,0 & 17,5 & 2,5 & 5,0 & 15,0 \\
Gostei moderadamente & 20,0 & 25,0 & 37,5 & 35,0 & 12,5 \\
Gostei muito & 17,5 & 15,0 & 22,5 & 10,0 & 7,5 \\
Gostei muitíssimo & 2,5 & 2,5 & 22,5 & 10,0 & 2,5 \\
\hline
\end{tabular}

importantes para a avaliação sensorial. As doses de irradiação têm efeito considerável na aparência e sabor do arroz cozido. Em estudos realizados por esses autores o arroz irradiado com dose de 2 kGy apresentou diferença significativa para a aceitabilidade global do arroz, sendo que a média obtida para o arroz não irradiado foi de 7,47 e, para o arroz irradiado com $2 \mathrm{kGy}$, a média foi de 4,60. Pelos resultados apresentados na Tabela 8 , pode ser observado que a amostra que recebeu irradiação de $1,0 \mathrm{kGy}$ foi a melhor aceita pelos provadores.

\subsection{Cor instrumental}

A Tabela 14 mostra os parâmetros de cor L, $\mathrm{a}^{\star}, \mathrm{b}^{\star}, \mathrm{Cro}-$ ma e $\mathrm{H}^{\circ}$ em arroz polido (Oryza sativa L.) irradiado e não irradiado.

Foi observada coloração inicial mais amarelada para o arroz irradiado com as doses de 3,0 e 5,0 kGy. Podemos verificar que, na análise sensorial do arroz cru, houve diferença estatística para as amostras de arroz irradiadas com doses de 3,0 e 5,0 kGy, quando comparadas com o controle e com as amostras irradiadas com doses de 0,5 e 1,0 kGy.

A cor é um importante parâmetro para a determinação da qualidade do arroz, devido à preferência do consumidor para arroz mais branco, como pode ser constatado pelos dados apresentados na Tabela 7, na qual as amostras que receberam notas menores foram as que apresentaram coloração mais amarelada (Tabela 14).

Tabela 12. Aceitabilidade (\%) para cor do arroz branco (Oryza sativa L.) irradiado e não irradiado.

\begin{tabular}{lrrrrr}
\hline & \multicolumn{5}{c}{ Tratamentos } \\
\hline \multicolumn{1}{c}{ Escala hedônica } & Controle & $\begin{array}{c}0,5 \\
\mathrm{kGy}\end{array}$ & $\begin{array}{c}1,0 \\
\mathrm{kGy}\end{array}$ & $\begin{array}{c}3,0 \\
\mathrm{kGy}\end{array}$ & $\begin{array}{c}5,0 \\
\mathrm{kGy}\end{array}$ \\
\hline Desgostei muitíssimo & 0,0 & 2,5 & 0,0 & 0,0 & 5,0 \\
Desgostei muito & 5,0 & 0,0 & 2,5 & 0,0 & 5,0 \\
Desgostei moderadamente & 7,5 & 2,5 & 0,0 & 10,0 & 15,0 \\
Desgostei ligeiramente & 25,0 & 15,0 & 2,5 & 2,5 & 22,5 \\
Indiferente & 10,0 & 17,5 & 5,0 & 15,0 & 10,0 \\
Gostei ligeiramente & 12,5 & 10,0 & 2,5 & 22,5 & 25,0 \\
Gostei moderadamente & 15,0 & 30,0 & 12,5 & 20,0 & 15,0 \\
Gostei muito & 20,0 & 17,5 & 42,5 & 22,5 & 0,0 \\
Gostei muitíssimo & 5,0 & 5,0 & 32,5 & 7,5 & 2,5 \\
\hline
\end{tabular}

Tabela 13. Aceitabilidade (\%) para sabor do arroz branco (Oryza sativa L.) irradiado e não irradiado.

\begin{tabular}{lrrrrr}
\hline \multicolumn{1}{c}{ Escala hedônica } & Controle & $\begin{array}{r}0,5 \\
\mathrm{kGy}\end{array}$ & $\begin{array}{c}1,0 \\
\mathrm{kGy}\end{array}$ & $\begin{array}{c}3 \\
\mathrm{kGy}\end{array}$ & $\begin{array}{c}5 \\
\mathrm{kGy}\end{array}$ \\
\hline Desgostei muitíssimo & 0,0 & 0,0 & 0,0 & 2,5 & 7,5 \\
Desgostei muito & 10,0 & 0,0 & 0,0 & 10,0 & 10,0 \\
Desgostei moderadamente & 0,0 & 10,0 & 2,5 & 5,0 & 10,0 \\
Desgostei ligeiramente & 10,0 & 12,5 & 7,5 & 12,5 & 22,5 \\
Indiferente & 10,0 & 7,5 & 2,5 & 15,0 & 20,0 \\
Gostei ligeiramente & 15,0 & 25,0 & 12,5 & 22,5 & 17,5 \\
Gostei moderadamente & 22,5 & 37,5 & 22,5 & 27,5 & 5,0 \\
Gostei muito & 20,0 & 7,5 & 35,0 & 2,5 & 7,5 \\
Gostei muitíssimo & 10,0 & 0,0 & 17,5 & 2,5 & 0,0 \\
\hline
\end{tabular}


Tabela 14. Cor instrumental em arroz cru irradiado e controle.

\begin{tabular}{cccccc}
\hline Tratamentos & $\mathrm{L}$ & $\mathrm{a}^{\star}$ & $\mathrm{b}^{*}$ & Croma $^{\mathrm{a}}$ & $\mathrm{H}^{\mathrm{o}}$ \\
\hline Controle & $67,93 \pm 0,6^{1 \mathrm{a} 2}$ & $0,9 \pm 0,0^{\mathrm{c}}$ & $9,96 \pm 0,6^{\mathrm{a}}$ & $10,0 \pm 0,6^{\mathrm{a}}$ & $95,17 \pm 0,3^{\mathrm{a}}$ \\
$0,5 \mathrm{kGy}$ & $70,46 \pm 2,05^{\mathrm{a}}$ & $1,0 \pm 0,1^{\mathrm{c}}$ & $10,2 \pm 0,7^{\mathrm{b}}$ & $10,25 \pm 0,8^{\mathrm{b}}$ & $95,59 \pm 0,2^{\mathrm{a}}$ \\
$1,0 \mathrm{kGy}$ & $71,30 \pm 1,04^{\mathrm{a}}$ & $1,06 \pm 0,15^{\mathrm{bc}}$ & $11,3 \pm 0,6^{\mathrm{bc}}$ & $11,38 \pm 0,6^{\mathrm{bc}}$ & $95,39 \pm 0,9^{\mathrm{a}}$ \\
$3,0 \mathrm{kGy}$ & $69,50 \pm 1,2^{\mathrm{a}}$ & $1,33 \pm 0,06^{\mathrm{ab}}$ & $12,4 \pm 0,2^{\mathrm{c}}$ & $12,54 \pm 0,2^{\mathrm{c}}$ & $96,10 \pm 0,2^{\mathrm{a}}$ \\
$5,0 \mathrm{kGy}$ & $70,30 \pm 1,6^{\mathrm{a}}$ & $1,60 \pm 0,2^{\mathrm{a}}$ & $13,9 \pm 0,3^{\mathrm{c}}$ & $14,05 \pm 0,3^{\mathrm{c}}$ & $96,53 \pm 0,8^{\mathrm{a}}$ \\
\hline
\end{tabular}

${ }^{1}$ Média \pm desvio padrão; ${ }^{2}$ médias seguidas de letras iguais nas colunas não diferem entre si pelo teste de Tukey, em nível de significância de $5 \%$ (p $<0,05$ ).

No caso deste experimento, observa-se na Tabela 14, que o valor expressa a luminosidade da amostra e varia de 0 a 100 , sendo que, quanto mais próximo de 100, mais clara é a amostra, e quanto mais distante, mais escura, não havendo diferença significativa da luminosidade das amostras submetidas à irradiação.

Com os valores $\mathrm{b}^{\star}$, indicando os parâmetros amarelos $(+)$, observou-se que houve diferença estatística entre as amostras. Segundo estudo realizado por Sirisoontaralak e Noomhorn (2006), o arroz muda a cor de branco cremoso para amarelado com o aumento das doses de irradiação, sendo que, até mesmo com uma baixa dose $0,2 \mathrm{kGy}$, já ocorre a mudança da cor. Resultados encontrados neste mesmo trabalho mostram que a amostra de arroz não irradiada apresentava valor $b^{*}$ de 9,72 e a amostra irradiada com dose de $2 \mathrm{kGy}$, valor de 14,66. Estas observações podem ser explicadas por desarranjo de glicosídeo e acoplamentos de peptídeo ocorridos durante a irradiação. Produtos de desarranjo como carbono e combinações aminos reagem (reação de Maillard). Outra causa provável de o arroz irradiado amarelar são as melanoidinas formadas devido à oxidação de fenóis (ROY; GHOSH; CHATTERJEE, 1991).

Segundo Lee (2007), a irradiação gama produz radicais livres e produtos de radiólise de açúcar e glicídios. Estes produtos e os radicais livres são capazes de se condensar e de produzir produtos coloridos durante o período após a irradiação.

Quanto aos valores de ângulo $\mathrm{H}$, observamos que não houve diferença significativa entre as amostras que foram tratadas com irradiação e não irradiada. Com relação ao Croma, observamos que as amostras foram estatisticamente diferentes, sendo a amostra controle a que apresentou o menor resultado e as doses de 0,5 e 1,0 kGy não apresentaram diferença estatística. As amostras com 3,0 e 5,0 kGy foram as que apresentaram as médias maiores.

\section{Conclusões}

Conclui-se que o uso da radiação gama, especialmente a dose de 1,0 kGy, mesmo apresentando diferença significativa $(\mathrm{p}<0,05)$ nas propriedades de pasta, proporcionou maior aceitação pelos provadores. Esta dose de irradiação não afetou a composição físico-química do arroz, assegurando maior vida-útil contra o ataque de insetos. Esta é, portanto, a dose recomendável para a conservação do arroz polido.

\section{Referências bibliográficas}

ARTHUR, V. et al. Influência do arroz irradiado na longevidade e reprodução de Sitophilus oryzae (L., 1763) (Col., Curculionidae). Energia Nuclear e Agricultura, v. 11, n. 1, p. 34-41, 1990.
ASSOCIATION OF OFFICIAL ANALYTICAL CHEMISTS - AOAC. Official methods of analysis of the association of analitical chemists. 18 ed. Arlington: AOAC, 2006.

BAO, J.; AO, Z.; JANE, J. Characterization of Physical Properties of Flour and

Starch Obtained from Gamma-Irradiated White Rice. Starch/Starke, v. 57, n. 10, p. 480-487, 2005.

COMPUSENSE INC. Compunsence five. São Paulo, 1986-1998. (CD-ROM).

DUTCOSKY, S. D. Análise sensorial de alimentos. Curitiba: Editora Universitária Champagnat, 1996.

FONTES, L. S; ARTHUR, V. Efeitos da radiação gama do Cobalto-60 em ovos de Tribolium castaneum (Herbst., 1797) (Coleoptera: Tenebrionidae). Scientia Agricola, v. 51, n. 3, p. 8-11, 1994.

GOMES, A. S.; MAGALHÃES JUNIOR, A. M. Arroz Irrigado no Sul do Brasil. Pelotas: Embrapa Clima Temperado, 2004.

GONZALEZ, L.; LIVORE, A.; PONS, B. Physico-chemical and cooking characteristics of some rice varieties. Brazilian Archives of Biology and Technology, v. 47, n. 1, 2004. Disponível em: <http://www. scielo.br/scielo.php?script=sci_arttext\&pid=\$1516-891320040001 00010\&lng=pt\&nrm=iso\&tlng=en>. Acesso em: 14 Fev. 2007.

GROPPO, G. A. Efeitos da Radiação gama do cobalto-60 na degradação de inseticidas aplicados em arroz e feijão armazenados. Piracicaba, 1988. 55p. Dissertação (Mestrado em Agronomia) - Centro de Energia Nuclear na Agricultura, Escola Superior de Agricultura Luiz de Queiroz, Universidade de São Paulo - USP.

INSTITUTO BRASILEIRO DE GEOGRAFIA E ESTATÍSTICA - IBGE. Estudo nacional da despesa familiar: tabela de composição de alimentos. 5 ed. Rio de Janeiro: Varela, 1999.

INTERNATIONAL ORGANIZATION FOR STANDARDIZATION - ISO. ISO 6647. Norme Internacionale: Riz-determination de la teneur en amylase. Geneve, 1987.

LEE, J. W. et al. The effect of irradiation temperature on the nonenzymatic browning reaction in cooked rice. Radiation Physics and Chemistry, v. 76, n. 5, p. 886-892, 2007.

MAIA, L. H. et al. Viscosidade de pasta, absorção de água e índice de solubilidade em água dos mingaus e índice de solubilidade em água dos mingaus desidratados de arroz e soja. Ciência e Tecnologia de Alimentos, v. 19, n. 3, p. 391-396, 1999.

MANCO, E. A. C. Efeito da radiação gama sobre inseticidas de grãos e produtos armazenados. Piracicaba, 1987.63 p. Dissertação (Mestrado em Agronomia) - Centro de Energia Nuclear na Agricultura, Escola Superior de Agricultura "Luiz de Queiroz", Universidade São Paulo - USP.

MINOLTA. Precise color communication: color control from feeling to instrumentation. Japão: Minolta, 1997.

NEWPORT SCIENTIFIC. Operation manual for series 4: instructions manual. Warriewood: Newport, 1998. 
ORGANIZACIÓN MUNDIAL DE LA SALUD. Inocuidad e idoneidad nutricional de los alimentos irradiados. Genebra: OMS, 1995.

PARIZZI, F. C. Avaliação da qualidade do arroz polido durante o armazenamento. Viçosa, 1993. 64p. Dissertação (Mestrado em Engenharia Agrícola) - Universidade Federal de Viçosa - UFV.

PEREIRA, J. Alterações na qualidade tecnológica de grãos de arroz (Oryza sativa L.) durante o armazenamento. Viçosa, 1996. 107 p. Dissertação (Mestrado em Ciência e Tecnologia de Alimentos) - Universidade Federal de Viçosa - UFV.

ROY, M. K.; GHOSH, S. K.; CHATTERJEE, S. R. Gamma-irradiation of rice grains. Journal of Food Science and Technology, v. 28, n. 6, p. 337-340, 1991.

SARTORI, M. R. et al. Ocorrência e especificidade de resistência ao inseticida malation em insetos-pragas de grãos armazenados no Estado de São Paulo. Coletanea do ITAL, v. 20, n. 2, p. 94-209, 1990.

SAS Institute. SAS user's guide: statistics. Version 8.0. Cary, 1999.

SATIN, M. La irradiación de los alimentos. Zaragoza: Editorial Acribia, S.A., 1997.

SIRISOONTARALAK, P.; NOOMHORM, A. Changes to physicochemical properties and aroma of irradiated rice. Journal of Stored Products Research, v. 42, n. 3, p. 264-276, 2006.

SUNG, W. Effect of gamma irradiation on rice and its food products. Radiation Physics and Chemistry, v. 73, n. 4, p. 224-228, 2005.

TAIPINA, M. S. et al. Novas tecnologias: Alimentos funcionais e a irradiação de alimentos. Higiene Alimentar, v. 17, n. 112, p. 31-34, 2003.
UNIVERSIDADE DE CAMPINAS - UNICAMP. Tabela brasileira de composição de alimentos. Disponível em <http://www.unicamp. br/nepa/taco >. Acesso em: 16 Ago. 2006.

UNIVERSIDADE DE SÃO PAULO. Faculdade de Ciências Farmacêuticas. Tabela de composição química de alimentos. Disponível em: <http://fcf.usp.br>. Acesso em: 16 Ago. 2005.

URBAIN, W. M. Biological effects of ionizing radiation. In: Food irradiation. Orlando: Academic Press, 1986. chap. 4, p. 83-117.

WEBB, B. D. Criteria of rice quality in the United States. In: JULIANO, B. O. Rice chemistry and technology. Minnesota: The American Association of Cereal Chemists, 1985. p. 403-442.

WIENDL, F. M. et al. Mortalidade e reprodução de Sitophilus zeamais Mots. em arroz irradiado. Boletim Científico do CENA, n.15, p. 19, 1974.

WU, D. et al. Effect of gamma irradiation on starch viscosity and physicochemical properties of different rice. Radiation Physics and Chemistry, v. 65, n. 1, p. 29-86, 2002.

YU, Y.; WANG, J. Effect of $\gamma$-ray irradiation on starch granule structure and physicochemical properties of rice. Food Research International, v. 40, n. 2, p. 297-303, 2007.

ZULETA, A. et al. Effect of gamma irradiation on the functional and nutritive properties of rice flours from different cultivars. Cereal Chemistry, v. 83, n. 1, p. 76-79, 2006. 